\title{
ENTREVISTAS PRELIMINARES EM PSICOTERAPIA DE FAMÍLIA: CONSTRUÇÃO DA DEMANDA COMPARTILHADA
}

Rebeca Nonato Machado

Este estudo teve como objetivo investigar o período de entrevistas preliminares com famílias, focando a avaliação diagnóstica, assim como as implicações da construção da demanda compartilhada e sua influência na adesão familiar ao tratamento. Entende-se que no período de entrevistas seja importante problematizar a queixa inicial, a qual é caracterizada por uma cristalização nos conflitos existentes na relação com o paciente identificado que impossibilita a construção de um posicionamento participante da família e favorece a manutenção de seu sofrimento.

BANCA:

Terezinha Féres-Carneiro (Orientadora)

Andrea Seixas Magalhães

Maria do Carmo C. de Almeida Prado

Data da defesa: 15/01/2010 